\title{
Preclinical and clinical studies of estrogen deprivation support the PDGF/Abl pathway as a novel therapeutic target for overcoming endocrine resistance in breast cancer
}

Marion T Weigel ${ }^{1+}$, Zara Ghazoui ${ }^{1+}$, Anita Dunbier ${ }^{1}$, Sunil Pancholi ${ }^{1}$, Mitch Dowsett ${ }^{1,2}$ and Lesley-Ann Martin ${ }^{1 *}$

\begin{abstract}
Introduction: The majority of breast tumors at primary diagnosis are estrogen receptor positive (ER+). Estrogen (E) mediates its effects by binding to the ER. Therapies targeting the estrogenic stimulation of tumor growth reduce mortality from ER+ breast cancer. However, resistance remains a major clinical problem.

Methods: To identify molecular mechanisms associated with resistance to E-deprivation, we assessed the temporal changes in global gene expression during adaptation to long-term culture of MCF7 human breast cancer cells in the absence of estradiol (E2), long term estrogen deprived (LTED), that leads to recovery of proliferative status and models resistance to an aromatase inhibitor (Al). The expression levels of proteins were determined by western blotting. Proliferation assays were carried out using the dual platelet derived growth factor receptor (PDGFR)/Abelson tyrosine kinase (Abl) inhibitor nilotinib. Luciferase reporter assays were used to determine effects on ER-mediated transactivation. Changes in recruitment of cofactors to the gene regulated by estrogen in breast cancer 1 (GREB1) promoter were determined by chromatin immunoprecipitation (ChIP). Gene expression data were derived from 81 postmenopausal women with ER+ BC pre-treatment and at two-weeks post-treatment with single agent anastrozole in a neoadjuvant trial.
\end{abstract}

Results: The PDGF/Abl canonical pathway was significantly elevated as early as one week post E-deprivation ( $P=1.94$ $\mathrm{E}-04)$ and this became the top adaptive pathway at the point of proliferative recovery ( $P=1.15 \mathrm{E}-07)$. Both PDGFR $\beta$ and Abl protein levels were elevated in the LTED cells compared to wild type (wt)-MCF7 cells. The PDGF/Abl tyrosine kinase inhibitor nilotinib, suppressed proliferation in LTED cells in the presence or absence of E. Nilotinib also suppressed ERmediated transcription by destabilizing the ER and reducing recruitment of amplified in breast cancer-1 (AIB1) and the CREB binding protein (CBP) to the promoter of the E-responsive gene GREB1. High PDGFRß in primary ER+ breast cancer of 81 patients prior to neoadjuvant treatment with an Al was associated with poorer antiproliferative response. Additionally PDGFR $\beta$ expression increased after two weeks of Al therapy (1.25 fold, $P=0.003)$.

Conclusions: These preclinical and clinical data indicate that the PDGF/Abl signaling pathway merits clinical evaluation as a therapeutic target with endocrine therapy in ER+ breast cancer.

\section{Introduction}

At primary diagnosis nearly $80 \%$ of breast cancers express estrogen receptor alpha $(E R \alpha)$ and proliferate in response to estrogen (E) [1]. Estrogen mediates its effects by binding to the ER, which subsequently

\footnotetext{
* Correspondence: Lesley-Ann.Martin@icr.ac.uk

+ Contributed equally

'Breakthrough Breast Cancer Centre, Institute of Cancer Research, 237

Fulham Road, London SW3 6JJ, UK

Full list of author information is available at the end of the article
}

associates with estrogen response elements (ERE) on target genes controlling proliferation and survival [2]. Classically, patients with ER+ breast cancer have been treated with endocrine agents, such as tamoxifen, which compete with $\mathrm{E}$ for the ER or aromatase inhibitors (AI), which block the conversion of androgens to estrogens [3]. Despite the efficacy of endocrine agents, both de novo and acquired resistance remain a significant clinical problem with up to $40 \%$ of patients relapsing on

\section{C) Biomed Central}


tamoxifen [4]. Although it was hoped that resistance to AIs would be less of a problem, many patients treated with AIs also exhibit resistance [4].

The molecular events that determine changes in the efficacy of endocrine therapies are not fully understood $[5,6]$. Preclinical and clinical studies provide support for mechanisms that involve cross-talk between ER and growth factor signaling pathways such as ERBB2/HER2 [5-7] but this is only overexpressed in about $10 \%$ of ER+ patients and is infrequently overexpressed with acquisition of resistance [8] indicating that alternative underlying molecular events remain to be discovered. In vitro models of resistance to endocrine therapy have relied on comparing the endocrine resistant cell lines with their isogenic wild type (wt) [9-16]. While this has provided valuable information highlighting many alterations in cell signaling, it has not addressed the temporal changes in genotype/phenotype that are directly associated with the acquisition of resistance. We used global gene expression analysis to assess the time-dependent changes in gene expression during the acquisition of resistance to estrogen deprivation using the ER+ breast cancer cell line MCF7. These data revealed the platelet derived growth factor (PDGF)/Ableson (Abl) canonical pathway as significantly upregulated as early as oneweek post-estrogen deprivation and revealed this to be the top adaptive pathway at the point of full resistance. In studies of molecular changes occurring in tumors in a cohort of patients treated with an AI in the neoadjuvant setting we found PDGFR $\beta$ expression to be significantly associated with poor antiproliferative response to therapy. Finally nilotinib, a selective inhibitor of PDGF/ Abl signaling was antiproliferative in LTED but not wtMCF7 cells. These laboratory and clinical studies indicate that the PDGF/Abl signaling pathway is worthy of clinical targeting to reverse or restrict resistance to AIs.

\section{Materials and methods}

\section{Cell culture and generation of the LTED cell line}

The human ER-positive breast cancer cell line MCF7, obtained from American Type Culture Collection (Rockville, MD, USA), was cultured in phenol red-free Roswell Park Memorial Institute medium (RPMI) medium supplemented with $10 \%$ fetal bovine serum, $10 \mu \mathrm{g} / \mathrm{ml}$ insulin and 1nM estradiol (E2) and was referred to as wild-type MCF7. The wt-MCF7 cells were passaged weekly and medium was replenished every two to three days. To model acquisition of resistance to long term estrogen deprivation (LTED) on an AI, wt-MCF7 cells were cultured in phenol red-free RPMI medium supplemented with $10 \%$ dextran charcoal-stripped bovine serum (DCC) [17] and $10 \mu \mathrm{g} / \mathrm{ml}$ insulin. Monolayers were harvested at the time points indicated during acquisition of resistance. Over a period of 40 weeks
LTED strains were generated in three independent experiments. For mechanistic studies LTED cells were passaged weekly and medium was replenished every two to three days. For all functional analysis cells were stripped of steroids and insulin over three days by culturing in phenol red-free RPMI 1640 supplemented with $10 \%$ DCC referred to as DCC-medium.

\section{Gene expression microarray analysis of cell lines}

RNA was extracted from the LTED monolayers using RNeasy columns (Qiagen, Crawley, UK) according to the manufacturer's protocol. RNA amplification, labeling and hybridization on HumanWG-6 v3 Expression BeadChips (Illumina, San Diego, CA, USA) were performed according to the manufacturer's instructions [18] to assess changes in gene expression during adaptation to LTED. Nine time-points between one and 40 weeks were assessed. The HumanWG-6 v3 Expression BeadChip covers more than 48,000 transcript probes and its annotation is publicly available. Raw data were filtered and normalized using Robust Spline Normalization method (RSN) within the Lumi package in Bioconductor [19]. Probes were discarded from further analyses if they were not detected in any of the samples (detection $P$-value $>1 \%$ ). Differential gene expression analyses between the multiple time points were performed in a pairwise fashion using the BRB Array Tool [20]. Pathway analyses were performed on the differentially expressed genes using Ingenuity Pathway Analysis [21] (ArrayExpress Accession number, EMTAB-922).

\section{Gene expression microarray analysis of breast tumors}

Samples analyzed in this study were collected in the IL1839/223 study, which received approval from an institutional review board at each site and was conducted in accordance with the 1964 Declaration of Helsinki11 and International Conference on Harmonization/Good Clinical Practice guidelines. Written informed consent was obtained from each patient before participation including approval for the biological analysis of residual tissue samples [22]. Core-cut tumor biopsies were collected using 14-gauge needles from 81 postmenopausal women with stage I to IIIB ER+ early breast cancer before and after two weeks of anastrozole treatment in the anastrozole only arm of a neoadjuvant trial [22]. Total RNA was extracted using RNeasy (Qiagen, Crawley, UK). RNA quality was assessed using an Agilent Bioanalyzer (Santa Clara, CA, USA). Samples were analyzed only if their RNA integrity values were greater than 5.0. RNA amplification, labeling, and hybridization on HumanWG-6 v2 Expression BeadChips were performed according to the manufacturer's instructions (Illumina, San Diego, CA, USA). Raw data were 
filtered and normalized using the same method as performed for the cell lines.

A proliferation metagene consisting of 101 genes was developed by selecting the intersection of two proliferation clusters from two public breast cancer datasets $[23,24]$. These two clusters were derived from each of these two breast cancer datasets independently as the smallest clusters that contained $95 \%$ of the genes previously reported to be associated with proliferation [25-27]. Spearman correlation analyses were performed to assess the relationship between the baseline expression of PDGFR $\beta$ and change in the proliferation metagene.

\section{Proliferation assays}

For proliferation assays, wt MCF7 cells were depleted of steroids for three days (stripped) by culturing in DCCmedium. Cells were subsequently seeded into 12-well plates at a density of $1 \times 10^{4}$ cells per well in DCC medium. LTED cells were treated similarly. Cells were left to acclimatize for 24 hours and were then treated with steroids or nilotinib (kindly provided by Novartis, Basel, Switzerland) for six days with daily changes. The cell number was determined using a Z1 Coulter counter (Beckman Coulter, High Wycombe, UK). Error bars represent \pm standard error of the means (s.e.m.). Survival assays were compared using two-way analysis of variance (ANOVA) with Bonferroni correction.

\section{SiRNA knockdown studies}

For siRNA knockdown, cells were plated in DCC medium on 96-well plates at a concentration of $2 \times 10^{3}$ (LTED) and $3 \times 10^{3}$ (MCF7) cells per well. After 24 hours cells were transfected with si control (non-targeting pool) or siRNA targeting $A B L, P D G F R B$ or the combination, using DharmaFECT 3 (Dharmacon, Horsham, UK) according to the manufacturer's protocol. The following day transfected cells were treated with DCC medium alone or in the presence of E2 $(0.01 \mathrm{nM})$. Cell growth was determined using CellTiter-glo luminescence assay (Promega, Southampton, UK) after 96 hours. Statistical analysis was performed using Student's T-test.

\section{Immmunoblotting}

Cell monolayers were washed with ice-cold PBS and whole cell extracts generated as previously described [28]. Equal amounts of protein $(50 \mu \mathrm{g})$ were resolved by SDS-PAGE and then subjected to immunoblot analysis. Antigen-antibody interactions were detected with ECLreagent (Amersham, Amersham, UK). Phospho- and total-proteins were detected using the following antibodies: anti-ER (Novocastra, Milton Keynes, USA), anti-
AKT, anti-phospho AKT, anti-phospho PDGFR $\beta$, antiPDGFR $\beta$, anti-phospho Abl, anti-Abl (Cell Signaling Technologies, Danvers, MA, USA), anti-actin, anti-phospho ERK1/2 (Sigma, Gillingham, UK), anti-ERK1/2 (Santa Cruz, Santa Cruz, CA, USA).

\section{Transcription assays}

Cell lines were stripped for three days and seeded in 24well plates at a density of $7 \times 10^{4}$ cells per well for MCF7 and $5 \times 10^{4}$ cells per well for LTED in DCC medium. Twenty-four hours later monolayers were transfected using Fugene 6 (Roche, Burgess Hill, UK), with $0.1 \mu \mathrm{g}$ of EREIItkluc (reporter) and $0.1 \mu \mathrm{g}$ of pCH110 ( $\beta$-galactosidase for normalization) according to the manufacturer's protocol, before treatment with the drugs indicated. After treatment for 24 hours the luciferase (Promega, Southampton, UK) and $\beta$-galactosidase (Galacto Star, Applied Biosystems, Bedford, MA, USA) activities were measured using a luminometer (TD20/20). Luciferase activity from triplicates was normalized and was expressed relative to vehicle treated control. Error bars represent \pm s.e.m.

\section{QRT-PCR}

Cells were plated at a density of $4 \times 10^{4}$ cells per well in 24-well plates into DCC medium. After 24 hours monolayers were transfected with siRNA as described above. RNA was extracted 48 hours later using the RNeasy kit (Qiagen). The mRNA was quantified using a NanoDrop 1000 spectrometer and reverse transcribed into cDNA using the SuperScript III First Strand Synthesis System for RT-PCR (Invitrogen, Grand Island, NY, USA). Expression levels of target genes were detected by qRTPCR using Assay-on-Demand primer/probe sets KIAA0674 (Hs00391480-m1), ABL1 (Hs01104721-m1) and PDGFRB (Hs01019583-m1).

\section{ChIP analyses}

LTED cells were treated with E2 alone or in combination with nilotinib for 45 minutes. Monolayers were fixed with $1 \%$ formaldehyde for ten minutes at room temperature and then quenched with glycine $(0.125 \mathrm{M})$. Chromatin was purified as previously described [28]. Chromatin complexes were immunoprecipitated with antibodies against ER (HC-20), AIB1 or CBP (Santa Cruz). Immune-complexes were purified and resulting DNA subjected to quantitative PCR analysis using SYBR green (Applied Biosystems, Bedford, MA, USA) in the presence of primers flanking the estrogen response element (ERE) within the promoter region of GREB1 (forward) 5'-GTGGCAACTGGGTCATTCTGA-3' and (reverse) 5'- CGACCCACAGAAATGAAAAGG-3'. Statistical analysis was performed using Student's T-test. 


\section{Results}

PDGF/Abl canonical pathway is strongly associated with adaptation to long term estrogen deprivation (LTED)

E-deprivation led to markedly decreased expression of the proliferation metagene (MG) after one week but near full recovery by nine weeks indicating resistance to E-deprivation by this time point (Figure 1). Thereafter, the expression of the MG remained stable. Moreover, global assessment of gene expression revealed stabilization of the gene signatures after this time-point. Based on this observation, further analyses were restricted to a triangular pairwise comparison of gene expression between wt MCF7 cells in the presence of $1 \mathrm{nM}$ E2 (modeling pre-treatment), one week post E-deprivation (modeling early response to an $\mathrm{AI}$ ) and at nine weeks post E-deprivation (modeling acquired resistance to an AI) (ArrayExpress Accession number, E-MTAB-922).

Comparison of gene expression in wt MCF7 cultured in the presence of E2 versus week one cells showed that 1,970 genes were down-regulated and 1,653 genes were up-regulated $(P<0.001 /$ FDR $=0.004)$. The down-regulated genes were mainly associated with metabolic and cell cycle pathways (Table 1). The up-regulated genes were associated with interferon and JAK/STAT canonical pathways indicative of increased cell stress. Comparison of week one versus week nine revealed 239 down-regulated genes and 236 up-regulated genes $(P<$ $0.001 / \mathrm{FDR}=0.03)$. Many of the down-regulated genes were involved in immune response pathways. The major up-regulated canonical pathways were involved in metabolism and cell cycle apparently reversing many of the changes seen by week one and consistent with the increase of the expression of the proliferation metagene.

Given the relatively similar proliferation status of wt MCF7 and week nine cells it was rationalized that comparison of wt MCF7 versus nine weeks E-deprivation would negate the overriding effect of the proliferation signature and unmask the underlying adaptive changes associated with acquired resistance. This analysis revealed 1,753 down-regulated genes and 1,758 up-regulated genes $(P<0.001 / \mathrm{FDR}=0.0048)$. All major upregulated canonical pathways were involved in classical cell signaling including PI3K/AKT/p70S6 and IGF1. Of particular interest the PDGF/Abl canonical pathway was significantly elevated as early as one-week post E-deprivation $\left(P=1.94 \times 10^{-4}\right)$ and was the top adaptive pathway at the point of resistance $\left(P=1.15 \times 10^{-7}\right)$. In order to assess the relevance of the PDGF/Abl pathway we

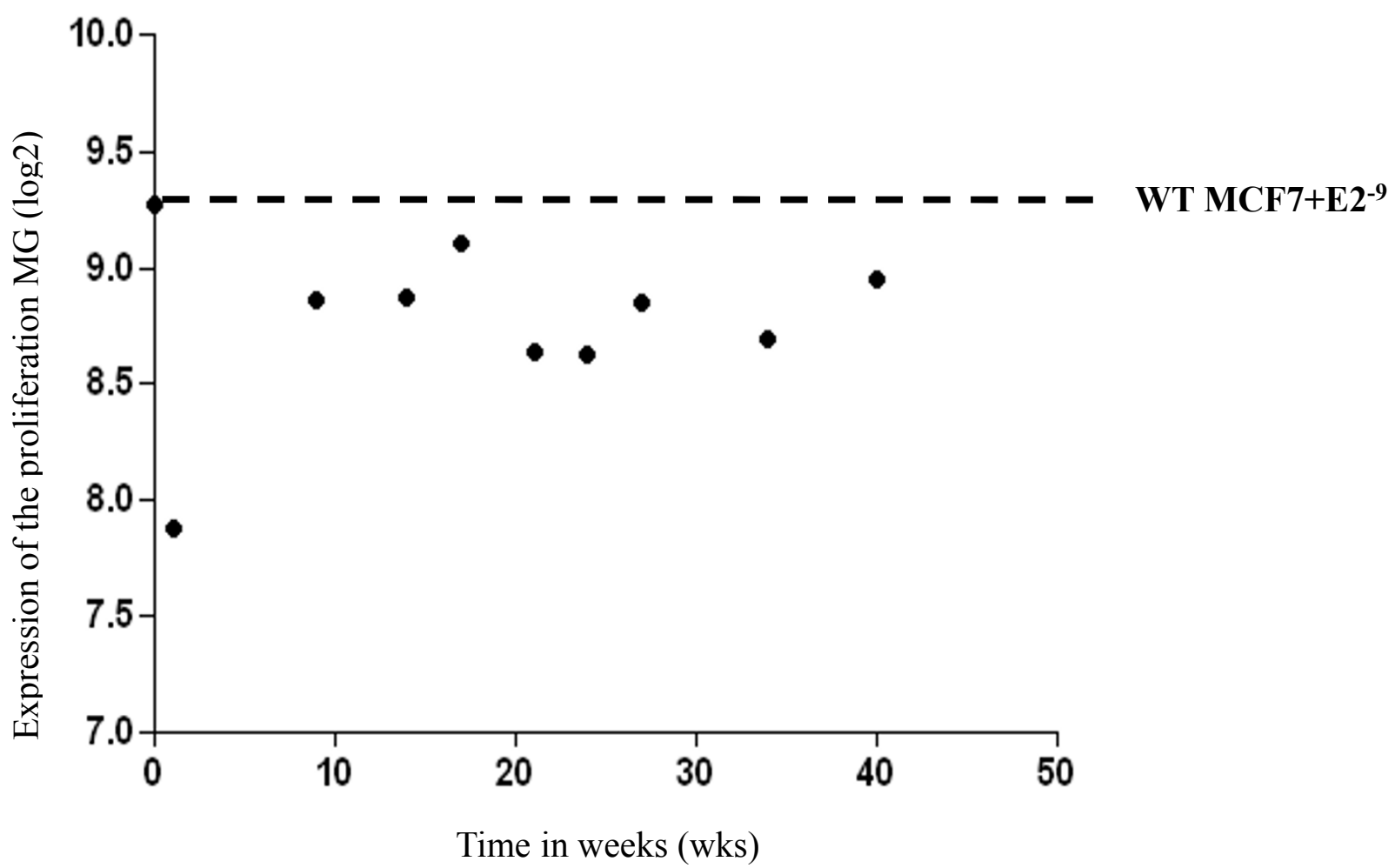

Figure 1 Temporal changes in the expression of the proliferation metagene. The dotted line represents the baseline proliferation metagene for the wt MCF7 cells cultured in E2 (1 nM). E2, estradiol; wt, wild type. 
Table 1 Comparison of the canonical pathways

\begin{tabular}{|c|c|c|c|}
\hline UP-REGULATED & $P$ value & DOWN-REGULATED & $P$ value \\
\hline Comparison A: Wt MCF7+E2 versus week 1 & & Comparison A: Wt MCF7+E2 versus week 1 & \\
\hline Interferon signalling & $\begin{array}{l}2.79 \mathrm{E}- \\
07\end{array}$ & Purine metabolism & $1.13 \mathrm{E}-12$ \\
\hline Molecular mechanisms of cancer & $\begin{array}{l}1.17 \mathrm{E}- \\
05\end{array}$ & Pyrimidine metabolism & $2.11 \mathrm{E}-10$ \\
\hline JAK/STAT signalling & $\begin{array}{l}2.72 \mathrm{E}- \\
05\end{array}$ & Protein ubiquitination pathway & $6.48 \mathrm{E}-08$ \\
\hline Germ cell-steroli cell junction signalling & $\begin{array}{l}2.76 \mathrm{E}- \\
05\end{array}$ & Role of BRCA1 in DNA damage response & $6.92 \mathrm{E}-08$ \\
\hline Inositol phosphate metabolism & $\begin{array}{l}1.15 \mathrm{E}- \\
04\end{array}$ & Mitotic roles of polo-like kinase & $5.72 \mathrm{E}-07$ \\
\hline IL-3 signalling & $\begin{array}{l}1.63 \mathrm{E}- \\
04\end{array}$ & Role of CHK proteins in cell cycle checkpoint control & $1.41 \mathrm{E}-06$ \\
\hline PDGF signalling & $\begin{array}{l}1.94 \mathrm{E}- \\
04\end{array}$ & ATM signalling & $3.06 \mathrm{E}-06$ \\
\hline Neuregulin signalling & $\begin{array}{l}2.15 \mathrm{E}- \\
04\end{array}$ & Cell cycle:G2/M DNA damage checkpoint regulation & $1.23 \mathrm{E}-05$ \\
\hline Erythropoietin signalling & $\begin{array}{l}2.31 \mathrm{E}- \\
04\end{array}$ & Cleavage and polyadenylation of pre-mRNA & $1.24 \mathrm{E}-04$ \\
\hline PI3K/AKT signalling & $\begin{array}{l}2.95 \mathrm{E}- \\
05\end{array}$ & Alanine and aspartate metabolism & $5.15 \mathrm{E}-04$ \\
\hline Comparison B: Week 1 versus week 9 & & Comparison B: Week 1 versus week 9 & \\
\hline Mitotic roles of polo-like kinase & $4.71 \mathrm{E}-08$ & Antigen presentation pathway & $8.88 \mathrm{E}-20$ \\
\hline $\begin{array}{l}\text { Role of CHK proteins in cell cycle checkpoint } \\
\text { control }\end{array}$ & $2.08 \mathrm{E}-07$ & Interferon signalling & $1.44 \mathrm{E}-17$ \\
\hline ATM signalling & $3.27 \mathrm{E}-07$ & Activation of IRF by cytosolic pattern recognition receptors & $2.48 \mathrm{E}-10$ \\
\hline Role of BRCA1 in DNA damage and response & 8.75E-06 & $\begin{array}{l}\text { Role of pattern recognition receptors in recognition of bacteria and } \\
\text { viruses }\end{array}$ & 2.37E-07 \\
\hline Hereditary breast cancer signalling & $2.08 \mathrm{E}-05$ & Dendritic cell maturation & $3.54 \mathrm{E}-06$ \\
\hline Pyrimidine metabolism & 3.34E-05 & Allograft rejection signalling & 7.64E-06 \\
\hline \multirow{4}{*}{$\begin{array}{l}\text { Cell cycle: G2/M DNA damage checkpoint } \\
\text { regulation }\end{array}$} & 1.57E-04 & Autoimmune thyroid disease signalling & $1.04 \mathrm{E}-05$ \\
\hline & & Graft-versus-host disease signalling & $1.21 \mathrm{E}-05$ \\
\hline & & Role of RIG1-like receptors in antiviral innate immunity & $1.39 \mathrm{E}-05$ \\
\hline & & Cross talk between dendritic cells and natural killer cells & $2.02 \mathrm{E}-05$ \\
\hline Comparison C: Wt MCF7+E2 versus week 9 & & Comparison C: Wt MCF7+E2 versus week 9 & \\
\hline PDGF signalling & $1.15 \mathrm{E}-07$ & Protein ubiquitination pathway & $1.63 \mathrm{E}-07$ \\
\hline Molecular mechanisms of cancer & 1.53E-07 & Purine metabolism & $6.49 \mathrm{E}-07$ \\
\hline Actin cytoskeleton signalling & 4.92E-07 & Pyrimidine metabolism & $7.92 \mathrm{E}-06$ \\
\hline Integrin signalling & $6.93 \mathrm{E}-07$ & Mitochondrial dysfunction & $1.25 \mathrm{E}-04$ \\
\hline PI3K/AKT signalling & $1.06 \mathrm{E}-06$ & Oxidative phosphorylation & $2.47 \mathrm{E}-04$ \\
\hline EGF signalling & $5.88 \mathrm{E}-06$ & Citrate cycle & 4.79 E-04 \\
\hline FAK signalling & 8.45E-06 & Role of BRCA1 in DNA damage response & $7.53 \mathrm{E}-04$ \\
\hline HGF signalling & $1.23 \mathrm{E}-05$ & Lysine degradation & $7.84 \mathrm{E}-04$ \\
\hline 14-3-3 mediated signalling & $1.30 \mathrm{E}-05$ & & \\
\hline Neuregulin signalling & $1.53 \mathrm{E}-05$ & & \\
\hline Ephrin Receptor Signaling & $1.66 \mathrm{E}-05$ & & \\
\hline |GF-1 Signaling & $1.85 \mathrm{E}-05$ & & \\
\hline ILK Signaling & 2.27E-05 & & \\
\hline Axonal Guidance Signaling & $3.12 \mathrm{E}-05$ & & \\
\hline JAK/Stat Signaling & $6.14 \mathrm{E}-05$ & & \\
\hline Insulin Receptor Signaling & $6.17 \mathrm{E}-05$ & & \\
\hline
\end{tabular}

ATM, ataxia teleangiectasia mutated; BRCA1, breast cancer type 1 susceptibility protein; CHK, csk-homologous kinase; E2, estradiol; EGF, epidermal growth factor; FAK, focal adhesion kinase; HGF, hepatocyte growth factor; IGF-1, insulin-like growth factor 1; IL-3, interleukin 3; ILK, integrin-linked kinase; IRF, interferon regulatory factor; JAK, Janus kinase; PDGF, platelet-derived growth factor; PI3K, phosphatidylinositol 3-kinase; RIG1, retinoid-inducible gene 1; STAT, Signal Transducer and Activator of Transcription; 
interrogated global gene transcription data from two publically available global gene transcription data sets from ER+ breast cancer cell lines (ZR-75.1, MDA MB 361 and HCC-1428) that had been adapted to LTED $[11,15]$. The PDGF/Abl pathway was not significantly altered within these data sets. Of note, unlike our LTED cells many of these cell lines lost or significantly reduced expression of ER during adaptation to estrogen deprivation. In order to determine the validity of our findings we, therefore, generated a further set of MCF7-LTED cells and found that the PDGF/Abl pathway was once again significantly increased indicating that acquisition of this pathway may be context specific.

\section{PDGFR expression is significantly associated with poor anti-proliferative response to aromatase inhibition in primary ER+ breast carcinomas}

Prior to further molecular characterization of the PDGF/ Abl pathway as a putative mechanism of resistance and potential target for therapy we sought evidence for its likely clinical relevance by interrogating global gene expression data from $81 \mathrm{ER}+$ patients who received the AI anastrozole as neoadjuvant (pre-surgical) treatment for 14 weeks. After two weeks on treatment, a second biopsy was taken to generate paired gene expression profiles during estrogen deprivation. PDGFRB showed no significant correlation with known predictive markers of hormone sensitivity such as ER or progesterone receptor (PGR) at baseline. No significant correlation with Ki67 or tumor size was observed. However, PDGFRB associated negatively with the Global Index of Dependence on Estrogen (GIDE) $(\mathrm{r}=0.41$ and $P=$ 0.0002) [29] that reflects the overall transcriptional response to E-deprivation. Furthermore, high PDGFRB levels pre-treatment were significantly associated with a poor response to the $\mathrm{AI}$ as measured using the proliferation metagene $(P=0.0006)$ (Figure $2 \mathrm{~A})$.

Additionally, pairwise comparison showed a significant increase in PDGFRB and PDGFRL expression after two weeks of estrogen deprivation (1.25-fold, $P=0.0003$, 1.43-fold, $P<0.001$ ), respectively (Figure $2 \mathrm{~B}$ and $2 \mathrm{C}$ ). The increase in PDGFRB and PDGFRL in response to neoadjuvant AI was further confirmed in an external clinical dataset from patients treated with two weeks of neoadjuvant letrozole (1.2-fold, $P=0.009$ and 1.51 -fold, $P<0.001)$ [30].

The PDGF/Abl pathway acts as a driver of proliferation in the LTED cells

Given the striking observation that PDGF/Abl was identified as the top adaptive pathway, expression levels of proteins included in the PDGF/Abl signaling pathway were investigated in the model systems. When compared to the wt-MCF7, the LTED cells expressed higher levels of PDGFR $\beta$ Moreover, an up-regulation of both PDGFR $\beta$ and Abl phosphorylation was detected in the LTED cell line. PDGFR $\alpha$ expression could not be detected (Figure 3A).

To determine the relevance of single or combined PDGFR and Abl inhibition on cell proliferation, shortterm (96 hours) siRNA knockdowns for the individual proteins or their combination were performed in MCF7 and LTED cells. The efficiency of the siRNA knockdown was assessed by qRT-PCR [See Additional file 1, Figure $\mathrm{S} 1]$. In the MCF7 cells neither PDGFR $\beta$ nor Abl knockdown had a significant inhibitory effect on proliferation in the presence or absence of E2. In contrast, knockdown of Abl in LTED cells reduced proliferation significantly in both the absence and presence of E2. An even greater anti-proliferative effect was observed using a siRNA knockdown of PDGFR $\beta$ in LTED cells in the absence and presence of E2. Of note, the combined knock down of both targets suppressed proliferation even further providing additional evidence of the relevance of this canonical pathway in adaptation to LTED (Figure 3B and 3C).

To establish the therapeutic relevance of the PDGF/ Abl pathway, we assessed the effect of nilotinib, a dual PDGFR and Abl inhibitor on cell proliferation. Increasing concentrations of nilotinib caused a slight but noticeable decrease in proliferation (Figure 4A and 4B) in wt MCF7 cells in the presence of $0.01 \mathrm{nM}$ estradiol (E2). However, this did not meet an IC50. Assessment of the anti-proliferative effect of nilotinib in the absence of E2 provided no further benefit compared to E2-deprivation alone. In contrast in the LTED model, nilotinib inhibited cell proliferation significantly both in the presence and absence of $\mathrm{E} 2$. The $\mathrm{IC}_{50}$ dose of nilotinib in this model $(2 \mu \mathrm{M})$ is within the specific dose range achievable in vivo [31].

\section{Inhibition of PDGFR/Abl reduces ER protein levels}

To elucidate the mechanism by which suppression of PDGFR/Abl mediated the anti-proliferative effect seen, wt MCF7 and LTED cells were treated with nilotinib in the presence and absence of E2 and effects on downstream signaling were assessed. In the presence of nilotinib, phosphorylation of both AKT and ERK1/2 was elevated irrespective of the presence of E2. Similarly, nilotinib induced a slight but noticeable increase in Abl. Strikingly, treatment with nilotinib suppressed the level of ER in both cell lines although this was more noticeable in the LTED cells (Figure 5).

\section{Inhibition of PDGFR/Abl signaling suppresses ER- mediated transcription in LTED cells}

To elucidate the effect of PDGFR/Abl inhibition on ERmediated transcription, cells were transiently transfected 
A
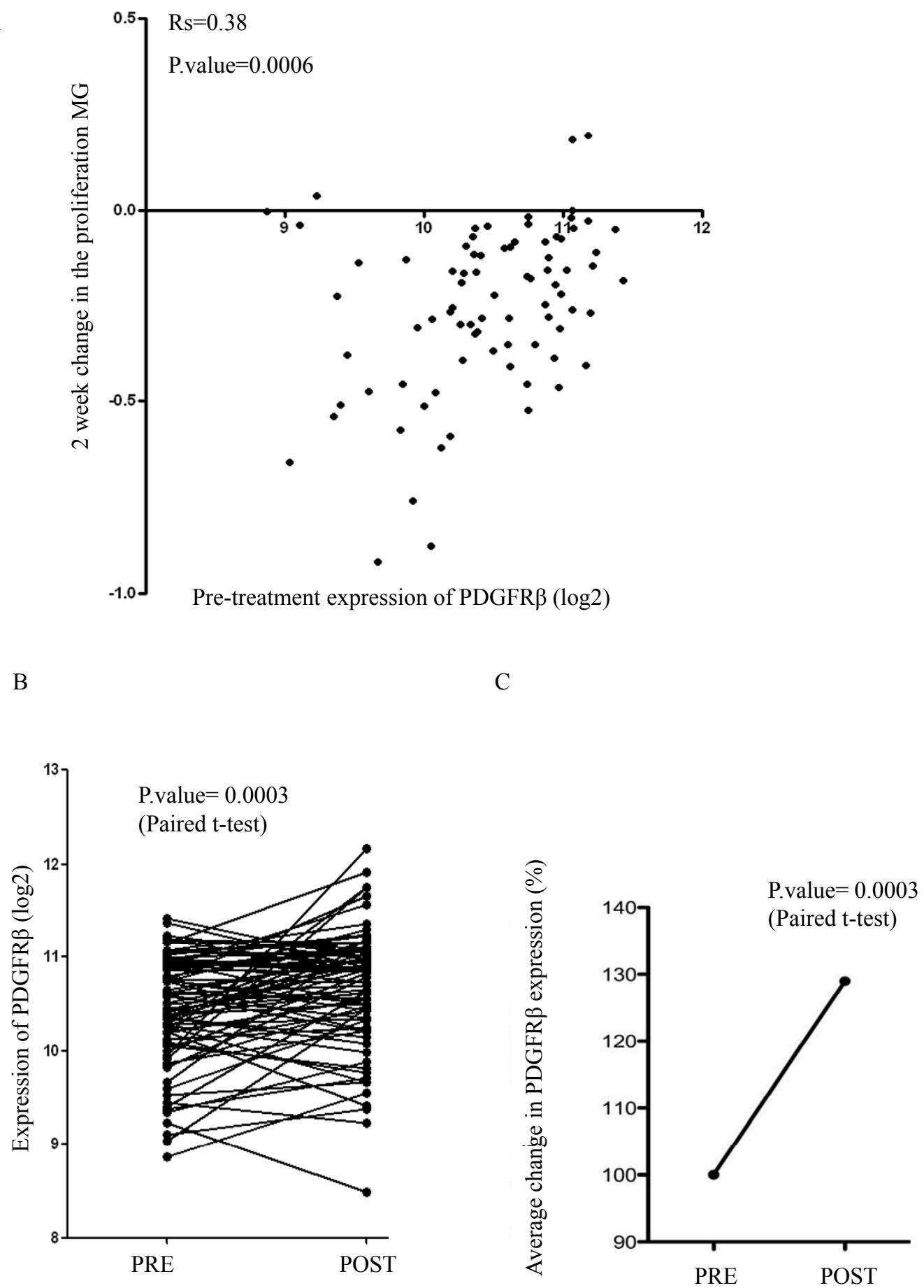

Figure 2 Expression of PDGFR $\boldsymbol{\beta}$ in clinical samples. A. Baseline expression of PDGFR $\beta$ versus two-week change in the proliferation metagene in 81 breast cancer patients. B. Expression changes of PDGFR $\beta$ in response to Al treatment. C. Average percentage change in PDGFR $\beta$ expression pre- and post-Al treatment. Al, aromatase inhibitor; PDGFR $\beta$, platelet derived growth factor receptor $\beta$.

with the ERE-luciferase reporter construct and treated with nilotinib in the presence and absence of E2 (Figure 6). In the wt-MCF7 cells nilotinib had no effect on ER/
ERE-mediated transactivation in the absence of E2 and a slight, but minimal inhibitory effect in the presence of E2 (Figure 6 A, B). However, in the LTED cells ER/ERE- 


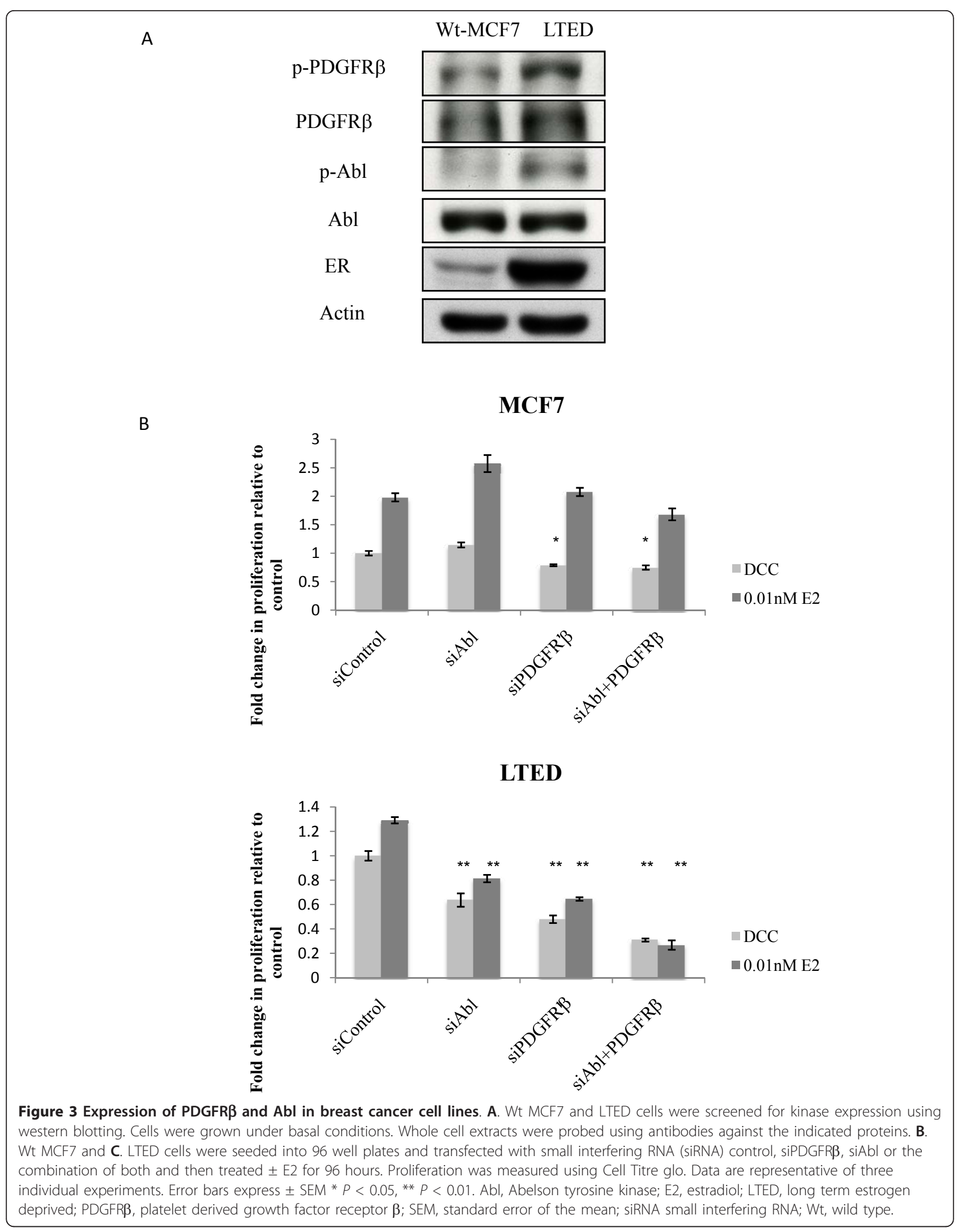




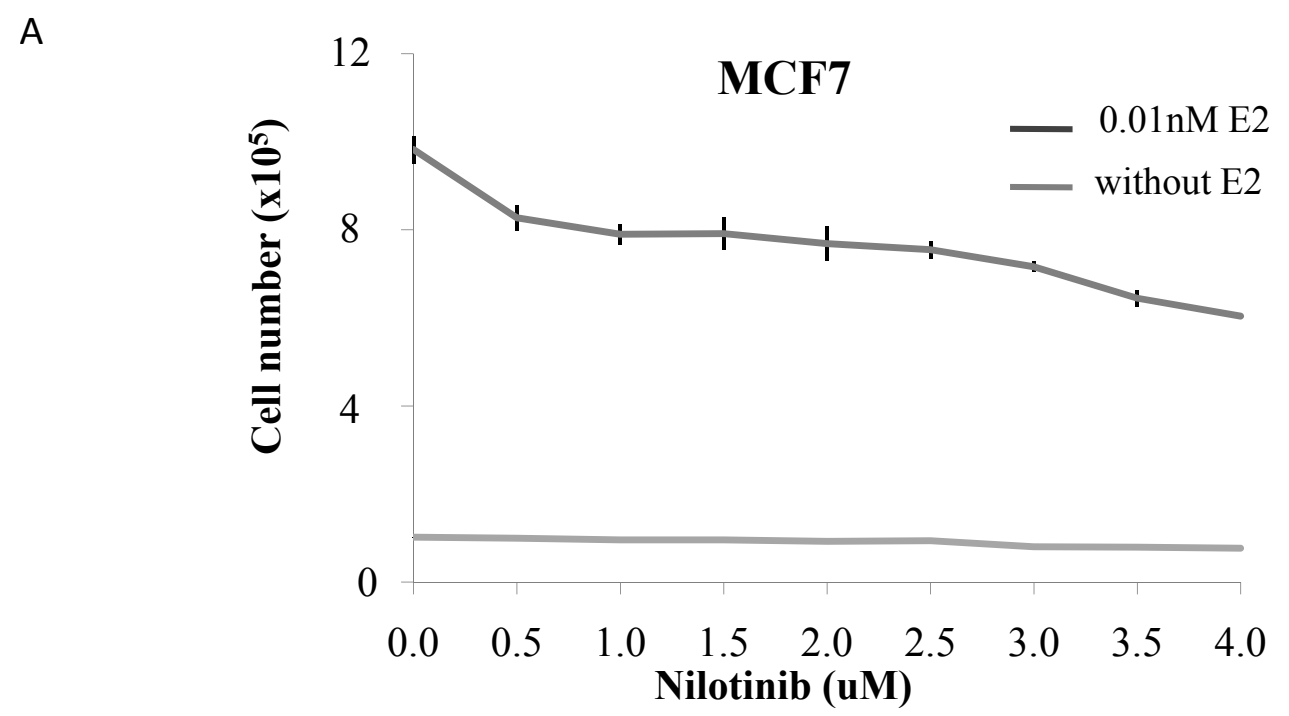

B

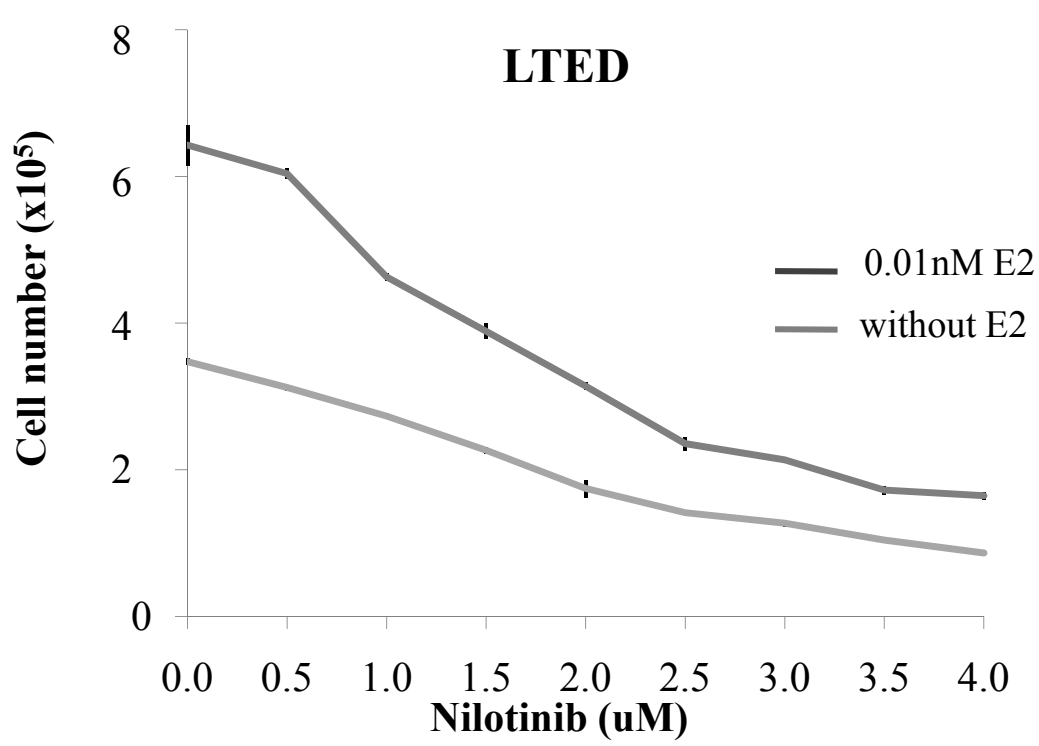

Figure 4 Inhibition of PDGFR $\boldsymbol{\beta}$ and Abl using nilotinib suppresses growth of LTED cells. The endocrine sensitive cell line MCF7 (A) and the resistant cell line LTED $(\mathbf{B})$ were seeded on 12-well plates and incubated for six days with various concentrations of nilotinib \pm E2. Cell proliferation was determined using a Coulter counter. Data are representative of three individual experiments. Error bars express \pm SEM of triplicate samples. Two way ANOVA showed a significant difference in cell survival in the LTED cells in the presence or absence of E2 at doses of $1 \mathrm{UM}$ and above $P<0.0001$. Abl, Abelson tyrosine kinase; ANOVA, analysis of variance; E2, estradiol; LTED, long term estrogen deprived; PDGFR $\beta$, platelet derived growth factor receptor $\beta$; SEM, standard error of the mean.

mediated transactivation was significantly inhibited in the absence of E2. Addition of E2 reduced the inhibitory effect of nilotinib on ER-mediated transcription, data in parallel with the effects on proliferation (Figure $6 \mathrm{C}, \mathrm{D}$ ).

We next examined the effect of nilotinib on the recruitment of ER together with its co-activators to the promoter of GREB1 (an endogenous E-regulated gene) using chromatin immunoprecipitation (ChIP). As ER/ ERE-mediated transcription was unaffected by nilotinib in the wt-MCF7 we focused our attention on the LTED cells. Nilotinib in the presence of E2 decreased the recruitment of ER, AIB1 and the CREB binding protein (CBP) to the ERE located within the GREB1 promoter compared to E2 alone (Figure 6E).

\section{Discussion}

Resistance to endocrine therapy is a major clinical problem in the treatment of breast cancer. Previously we, 


\section{MCF7 LTED}

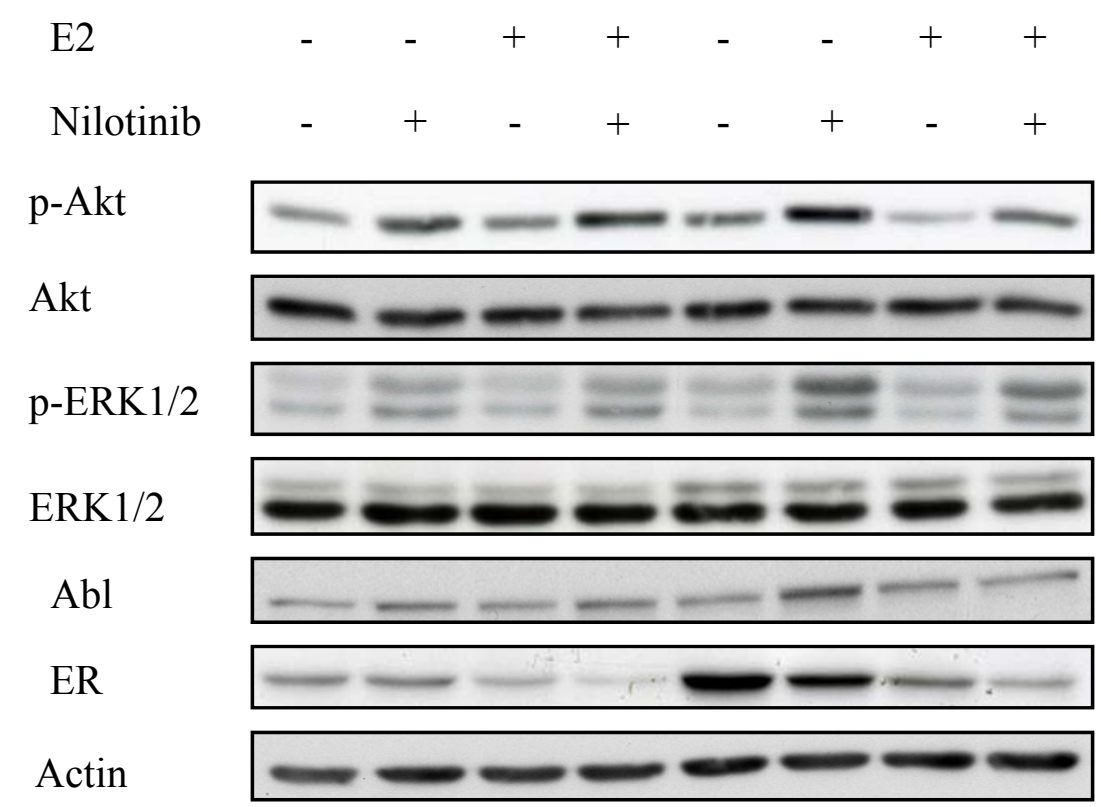

Figure 5 Inhibition of PDGFR $\beta$ and Abl with nilotinib reduces ER protein stability. Wt MCF 7 and LTED cells were treated with nilotinib (2 $\mu \mathrm{M}) \pm \mathrm{E} 2$ for 24 hours. Cell monolayers were subsequently harvested and whole cell extracts probed for the proteins indicated. Data shown are representative of three independent experiments. Abl, Abelson tyrosine kinase; E2, estradiol; LTED, long term estrogen deprived; Wt, wild type.

along with others, have highlighted the role of cross-talk between the ER and ERBB2/HER2 signaling pathways leading to endocrine resistance as a result of ligandindependent activation of the ER or by the generation of an E-hypersensitive phenotype [10,14,32-35]. In the current study, we used a novel strategy to try to identify temporal changes in the transcriptome associated with the acquisition of resistance to LTED. Using a proliferation MG we showed that proliferation recovered, that is, resistance occurred, as early as nine weeks post Edeprivation.

Comparison of the wt-MCF7 cells (modeling pretreatment) versus MCF7 cells after one week of E-deprivation (modeling a patient responding to an $\mathrm{AI}$ ) highlighted proliferation and metabolic canonical pathways as the most significantly down-regulated. This is in keeping with previous short term clinical investigations of AIs [29,36,37]. Of note, the JAK/STAT and interferon canonical pathways were markedly up-regulated after one week of E-deprivation. It has been shown that signal transducer and activator of transcription 1 (STAT1) is particularly important in activating IFN- $\gamma$ and its antitumor effects. In addition to inhibiting proliferation and survival, IFN- $\gamma$ enhances the immunogenicity of tumor cells, in part, by enhancing the STAT1-dependent expression of MHC proteins [38].

Changes in transcription profiles after one week of Edeprivation with nine weeks of E-deprivation (modeling a patient with acquired endocrine resistant disease) in part reflected the reinstatement of proliferation, but also showed that IFN signaling and several canonical pathways associated with immune recognition were down regulated over that period. Clinical studies have shown that in triple negative breast cancer impaired immune response might be linked with the development of distant metastases. Indeed, high expression of an immune response gene expression module was associated with a significantly better outcome in two independent studies $[39,40]$. Our data suggest that part of these immune signatures may emanate from epithelial cells and not from an inflammatory infiltrate.

Comparison of the wt MCF7 cells with nine weeks post E-deprivation negated the overriding effect of the proliferation signature and unmasked the underlying adaptive changes associated with acquired resistance. The major up-regulated canonical pathways were identified as all being classically associated with cell signaling including PI3K/AKT/p70S6 and IGF1 all of which have been associated with poor prognosis in previous studies of ER+ breast cancer [41-46]. Of particular note, two recent clinical studies TAMRAD [47] and BOLERO-2 [48] have reported substantially greater activity of the mTOR inhibitor everolimus (RAD001) in the metastatic setting after relapse on AI therapy.

Our most striking observation, however, was the alteration in PDGF/Abl signaling. This canonical 
$\mathrm{A}^{-}$

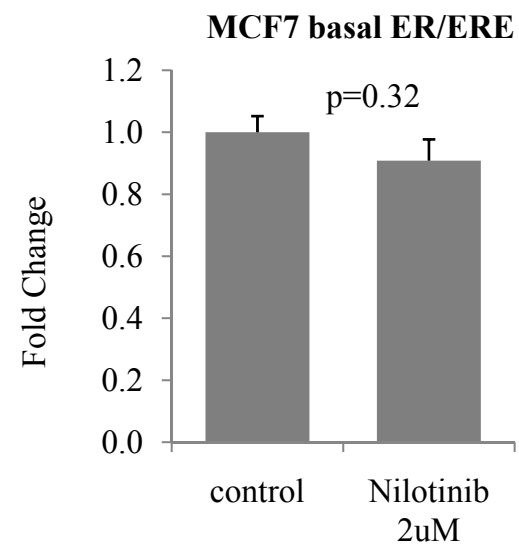

$\mathrm{C}$

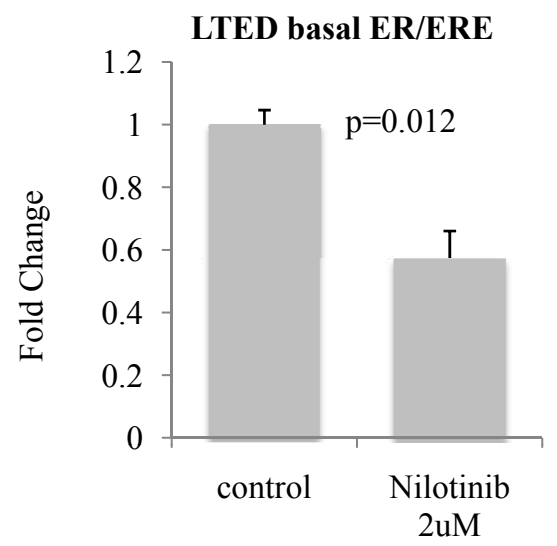

E

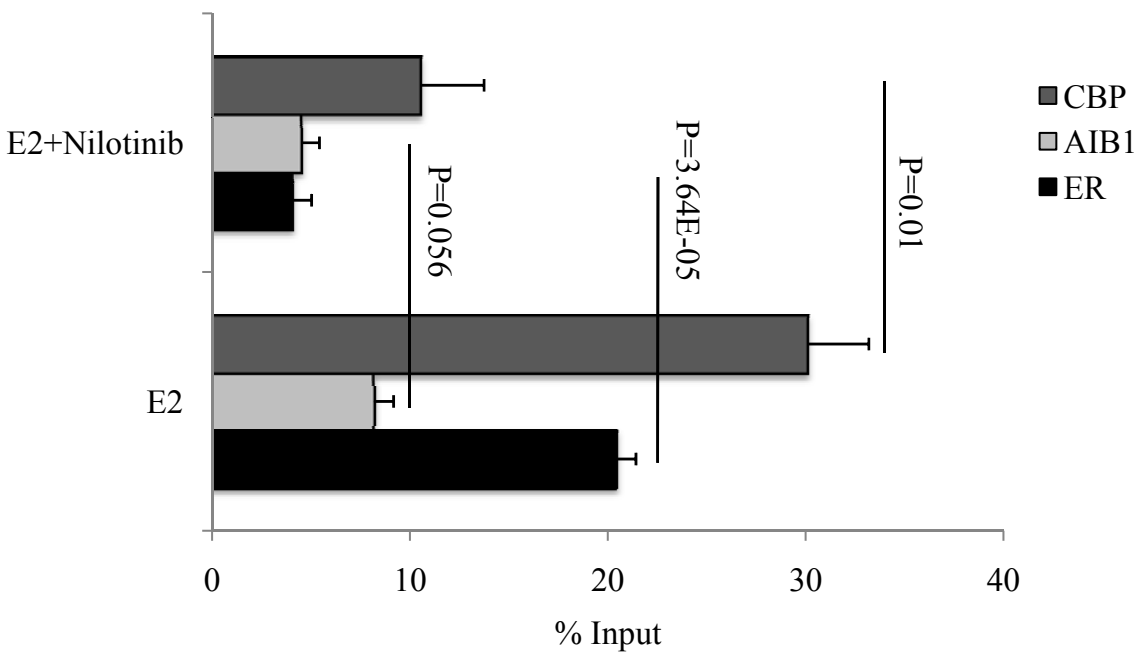

B

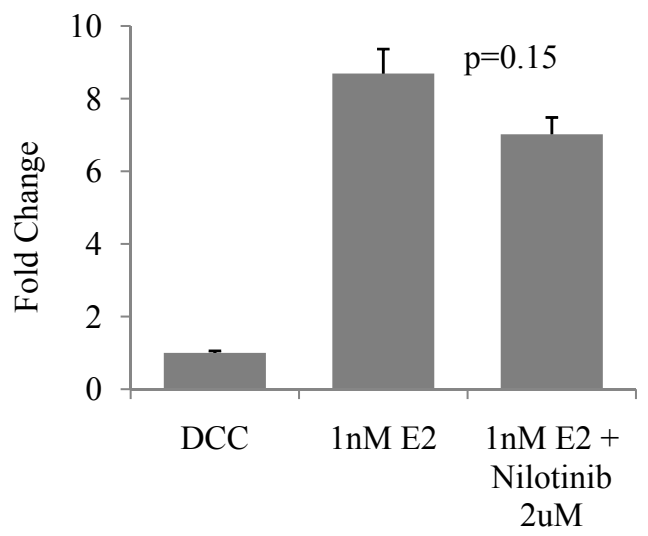

D LTED E2-mediated ER/ERE

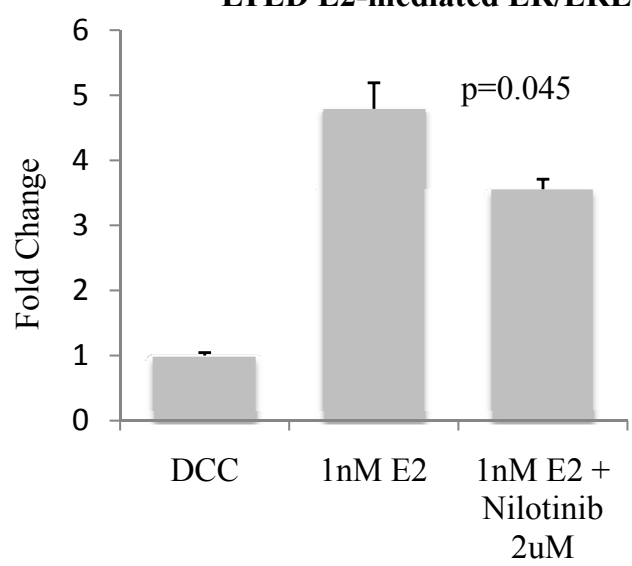

Figure 6 Inhibition of PDGFR/Abl suppresses ER/ERE-mediated transactivation. Cells were transfected with an artificial luciferase reporter and treated as indicated. Luciferase activity was measured and normalized to DCC to quantify ER-transactivation. A and $\mathbf{B}$ show the effect of nilotinib on ER-mediated transcription in wt-MCF7. $\mathbf{C}$ and $\mathbf{D}$ show the effect of nilotinib on ER-mediated transcription in LTED cells. The data shown are representative of four individual experiments. Bars represent \pm SEM of triplicate samples. E. ChIP analysis to determine ER, AIB1 and CBP recruitment to the GREB1 promoter was performed. Cell monolayers were serum starved for 24 hours and treated for 45 minutes with E2 (1 $\mathrm{nM})$ and nilotinib $(4 \mu \mathrm{M})$ as indicated. Antibodies against total ER $\alpha$, AlB1 and CBP were used to pull-down protein complexes and to assess their recruitment to the ERE located in the GREB1 promoter by q-PCR. Data shown are representative of two independent experiments. Abl, Abelson tyrosine kinase; AIB1, amplified in breast cancer 1; CBP, CREB binding protein; ChIP, chromatin immunoprecipitation; DCC, dextran charcoalstripped bovine serum; E2, estradiol; ER, estrogen receptor; ERE, estrogen response element; LTED, long term estrogen deprived; SEM, standard error of the mean; wt, wild type. 
pathway was elevated as early as one week post E-deprivation. Although the over riding effect of E-deprivation after one week was suppression of proliferation, pathways such as PDGF/Abl, neuregulin (Her2) and PI3 kinase were up-regulated and may be indicative of early adaptive responses pre-dating cell growth. Surprisingly, PDGF/Abl became the top adaptive pathway at the point of resistance superseding both the neuregulin and PI3 kinase canonical pathways, both of which have been previously reported to be strongly associated with endocrine resistance [15].

PDGF receptors (PDGFR) contain an intracellular tyrosine kinase domain whose activation is dependent on binding of PDGF resulting in stimulation of several intracellular pathways, leading to cell proliferation and survival [49]. PDGF can promote tumor growth via autocrine stimulation of malignant cells, overexpression or overactivation of PDGFRs, or by stimulating tumor angiogenesis. For this reason, targeting PDGF signaling has become of interest for the development of anticancer therapeutics. Two main approaches have been taken to inhibit PDGFR signaling in cancer: direct targeting of tumor cells proliferating in response to PDGF signaling or indirect inhibition of tumor growth by targeting pericytes to decrease angiogenesis [49]. Abl is a Src-like nonreceptor protein kinase that acts down-stream of the PDGFR. Abl is involved in the regulation of cell proliferation, apoptosis, adhesion, cell migration and stress response [50,51]. The existence of C-terminal DNAbinding motifs and nuclear localization signals enables Abl to shuttle between cytoplasmic and nuclear compartments [52,53]. Activating translocations of $A B L$, such as $B C R-A B L$, are pivotal for the development of chronic myelogenous leukemia [54].

To determine the clinical significance of our finding we used global gene transcription data from a cohort of patients with ER+ primary breast cancer before and after two weeks of neoadjuvant AI therapy. Notably PDGFRB and PDGFRL expression was increased after two weeks of E-deprivation (Figure $2 B$ ). Moreover, low PDGFRB levels pre-treatment were associated with a better response to the AI. This would support the possibility that expression of PDGFR $\beta$ may be an early marker of de novo and/or acquired endocrine resistance. In support of our finding a recent clinical study showed that elevated levels of stromal PDGFR $\beta$ were associated with a poor prognosis in breast cancer patients [55].

To investigate the role of PDGF/Abl signaling during adaptation to LTED we selected the dual PDGFR/Abl kinase inhibitor nilotinib. Treatment of the wt MCF7 cells in the presence of E2 modeling a patient at primary diagnosis showed that nilotinib as a monotherapy caused a concentration-dependent decrease in proliferation but this was far less compared with Edeprivation alone. In order to model the effect of nilotinib in patients who have relapsed on an AI and for whom treatment has ceased we treated the LTED cells with $0.01 \mathrm{nM}$ E2. In keeping with our previous data [56] we showed that E2 caused an increase in proliferation (1.85-fold) although the magnitude of the response was far less than that seen in the MCF7 cells (12-fold). The LTED cells were significantly sensitive to nilotinib in the presence of $\mathrm{E} 2$. The $\mathrm{IC}_{50}$ dose of nilotinib in this model was within the range of plasma levels achieved clinically. Most strikingly, proliferation was substantially lower with nilotinib in the absence of E2. This suggests that in the clinical setting nilotinib may be useful in combination with an AI to delay the onset of resistance or indeed to prolong the efficacy of the AI in the metastatic setting.

In order to determine whether PDGFR $\beta$ or Abl was dominant in the LTED phenotype, we used siRNA knockdown. Surprisingly both kinases appeared integral to the phenotype, although suppression of PDGFR $\beta$ inhibited proliferation to a greater degree. Assessment of the effect of nilotinib on downstream signaling in both the wt MCF7 and the LTED in the presence and absence of E2 showed that nilotinib increased both AKT and ERK1/2 phosphorylation. Studies with dasatinib, which targets Src-family kinases and Abl have shown similar increases in signaling via these pathways. It has been postulated that this might be indicative of an early resistance mechanism to inhibition of these non-receptor tyrosine kinase pathways [57].

Of particular note, nilotinib significantly decreased ER levels. It has been demonstrated using transient transfection that Abl regulates ER protein stability via phosphorylation of tyrosine 52 and 219 [58]. Similarly, Abl has been shown to phosphorylate AIB1, a nuclear coactivator for ER, providing further evidence for the role of $\mathrm{Abl}$ in modulating ER genomic function [59]. As the LTED cells remain dependent on the ER for proliferation [12] we hypothesized that inhibition of Abl may suppress ER-mediated transcription. Indeed, we were able to demonstrate that nilotinib significantly reduced ER/ERE transactivation as a result of decreased recruitment of ER, AIB1 and CBP (Figure 6).

These data suggest that PDGFR/Abl signaling may provide a therapeutic target in $\mathrm{ER}+$ breast cancer. Recently, the clinical significance of impeding c-kit and PDGFR in combination with aromatase inhibition has been addressed in two single arm clinical trials in ER+ breast cancer patients $[60,61]$. In the first pre-operative study ER+ patients were treated with letrozole plus imatinib, a c-Kit/PDGFR/Abl receptor tyrosine kinase inhibitor, for three months. Of the ten evaluable patients, nine achieved clinical partial response and one had 
stable disease. In a second single arm study, postmenopausal women with ER+ disease and no prior endocrine therapy for metastatic breast cancer who expressed PDGFR and/or c-kit, were treated with letrozole plus imatinib. Partial response was achieved in seven patients (15.6\%) and stable disease was observed in 20 patients (44\%). The disadvantage of these studies is that the AI alone was not assessed and, therefore, it is impossible to ascertain the benefit gained by the combination. To address this, a two arm study comparing an AI versus AI plus imatinib or nilotinib would be required in which patients with ER+/PDGFR+ breast cancer would be eligible.

\section{Conclusions}

Using temporal global gene expression data together with functional analysis we have identified a novel interaction between ER and the PDGF/Abl signal transduction pathway that occurs during adaptation to LTED and which appears partly responsible for the resistant phenotype. One of the major limitations of this study is the use of a single cell line model of acquired resistance to E-deprivation and as such these finding may be context specific. However, we were able to confirm the clinical relevance of these in vitro observations in two independent and heterogeneous cohorts of patients treated with an AI.

Taken together these data suggest that PDGFR $\beta$ may provide a novel biomarker of early resistance to AI therapy and with further in vitro and in vivo validation may prove to be a novel therapeutic target in treatment and/ or avoidance of endocrine resistance in certain patient populations.

\section{Additional material}

Additional file 1: Figure S1: siRNA knockdown of PDGFR $\beta$ and $A b l$ reduces mRNA expression. Cells were transfected with siRNA against PDGFR $\beta, A b l$ or the combination of the two. Forty-eight hours after transfection mRNA was extracted, quantified and reverse transcribed. Expression levels of genes were detected using QRT-PCR. Error bars represent \pm SEM

\footnotetext{
Abbreviations

Abl: Abelson tyrosine kinase; Al: aromatase inhibitor; AIB1: amplified in breast cancer 1; CBP: CREB binding protein; ChIP: chromatin immunoprecipitation; DCC: dextran charcoal-stripped bovine serum; E2: estradiol; ERBB2: human epidermal growth factor receptor 2; ER: estrogen receptor; ERE: estrogen response element; GREB1: gene regulated by estrogen in breast cancer 1; IFN: interferon; IGF1: insulin like growth factor; LTED: long term estrogen deprived; MG: metagene; PBS: phosphate buffered saline; PDGFR: platelet derived growth factor receptor; PI3K: phosphatidylinositol 3-kinases; RT-PCR: reverse transcriptase polymerase chain reaction; s.e.m.: standard error of the mean; siRNA: small interfering RNA; STAT: signal transducer and activator of transcription; wt: wild type.
}

\section{Acknowledgements}

We thank the Mary-Jean Mitchell Green Foundation, Breakthrough Breast Cancer and Deutsche Krebshilfe for generous funding. We also acknowledge NHS funding to the Royal Marsden Hospital's NIHR Biomedical Research Centre.

\section{Author details}

${ }^{1}$ Breakthrough Breast Cancer Centre, Institute of Cancer Research, 237 Fulham Road, London SW3 6JJ, UK. ²Department of Academic Biochemistry, The Royal Marsden Hospital, Fulham Road, London, UK SW3 6JB, UK.

\section{Authors' contributions}

MTW was involved in the design of the study, carried out the in vitro research and helped draft the manuscript. ZG carried out the bioinformatics and helped draft the manuscript. AD was involved in the bioinformatics analyses. SP helped generate the LTED cell line and was involved in the molecular research. MD critically reviewed the manuscript. LAM developed the concept and experimental design, generated the LTED cell line, carried out the ChIP assays and wrote the manuscript. All authors have read and approved the final manuscript.

\section{Competing interests}

MTW, ZG, AD and SP have no conflict of interest that could be perceived as prejudicing the impartiality of the research reported; MD receives research funding, honoraria for advisory boards and lecture fees from AstraZeneca, Novartis and Roche: LAM receives academic research funding from AstraZeneca and Pfizer.

Received: 21 December 2011 Revised: 30 March 2012 Accepted: 18 May 2012 Published: 18 May 2012

\section{References}

1. Dowsett M, Houghton J, Iden C, Salter J, Farndon J, A'Hern R, Sainsbury R, Baum M: Benefit from adjuvant tamoxifen therapy in primary breast cancer patients according oestrogen receptor, progesterone receptor, EGF receptor and HER2 status. Ann Oncol 2006, 17:818-826.

2. Green KA, Carroll JS: Oestrogen-receptor-mediated transcription and the influence of co-factors and chromatin state. Nat Rev Cancer 2007, 7:713-722.

3. Smith IE, Dowsett M: Aromatase inhibitors in breast cancer. $N$ Engl J Med 2003, 348:2431-2442.

4. Markopoulos CJ: Minimizing early relapse and maximizing treatment outcomes in hormone-sensitive postmenopausal breast cancer: efficacy review of Al trials. Cancer Metastasis Rev 2010, 29:581-594.

5. Ali S, Coombes RC: Endocrine-responsive breast cancer and strategies for combating resistance. Nat Rev Cancer 2002, 2:101-112.

6. Arpino G, Wiechmann L, Osborne CK, Schiff R: Crosstalk between the estrogen receptor and the HER tyrosine kinase receptor family: molecular mechanism and clinical implications for endocrine therapy resistance. Endocr Rev 2008, 29:217-233.

7. Musgrove EA, Sutherland RL: Biological determinants of endocrine resistance in breast cancer. Nat Rev Cancer 2009, 9:631-643.

8. Ellis MJ, Tao Y, Young O, White S, Proia AD, Murray J, Renshaw L, Faratian D, Thomas J, Dowsett M, Krause A, Evans DB, Miller WR, Dixon JM: Estrogen-independent proliferation is present in estrogen-receptor HER2-positive primary breast cancer after neoadjuvant letrozole. J Clin Oncol 2006, 24:3019-3025.

9. Coutts AS, Murphy LC: Elevated mitogen-activated protein kinase activity in estrogen-nonresponsive human breast cancer cells. Cancer Res 1998, 58:4071-4074.

10. Sabnis GJ, Jelovac D, Long B, Brodie A: The role of growth factor receptor pathways in human breast cancer cells adapted to long-term estrogen deprivation. Cancer Res 2005, 65:3903-3910.

11. Masri S, Phung S, Wang X, Wu X, Yuan YC, Wagman L, Chen S: Genomewide analysis of aromatase inhibitor-resistant, tamoxifen-resistant, and long-term estrogen-deprived cells reveals a role for estrogen receptor. Cancer Res 2008, 68:4910-4918.

12. Martin LA, Pancholi S, Chan CM, Farmer I, Kimberley C, Dowsett M, Johnston SR: The anti-oestrogen ICI 182,780, but not tamoxifen, inhibits the growth of MCF-7 breast cancer cells refractory to long-term 
oestrogen deprivation through down-regulation of oestrogen receptor and IGF signalling. Endocr Relat Cancer 2005, 12:1017-1036.

13. Gee JM, Robertson JF, Gutteridge E, Ellis IO, Pinder SE, Rubini M, Nicholson RI: Epidermal growth factor receptor/HER2/insulin-like growth factor receptor signalling and oestrogen receptor activity in clinical breast cancer. Endocr Relat Cancer 2005, 12(Suppl 1):S99-S111.

14. Santen RJ, Song RX, Masamura S, Yue W, Fan P, Sogon T, Hayashi S, Nakachi K, Eguchi H: Adaptation to estradiol deprivation causes upregulation of growth factor pathways and hypersensitivity to estradiol in breast cancer cells. Adv Exp Med Biol 2008, 630:19-34.

15. Miller TW, Hennessy BT, Gonzalez-Angulo AM, Fox EM, Mills GB, Chen H, Higham C, Garcia-Echeverria C, Shyr Y, Arteaga CL: Hyperactivation of phosphatidylinositol-3 kinase promotes escape from hormone dependence in estrogen receptor-positive human breast cancer. $J$ Clin Invest 2010, 120:2406-2413.

16. Plaza-Menacho I, Morandi A, Robertson D, Pancholi S, Drury S, Dowsett M, Martin LA, Isacke CM: Targeting the receptor tyrosine kinase RET sensitizes breast cancer cells to tamoxifen treatment and reveals a role for RET in endocrine resistance. Oncogene 2010, 29:4648-4657.

17. Darbre PD, Curtis S, King RJ: Effects of estradiol and tamoxifen on human breast cancer cells in serum-free culture. Cancer Res 1984, 44:2790-2793.

18. Illumina. [http://www.llumina.com].

19. Bioconductor. [http://www.bioconductor.org].

20. BRB Array Tool. [http://linus.nci.nih.gov/BRB-ArrayTools.html].

21. Ingenuity Systems Pathway Analysis. [http://www.ingenuity.com/index. html].

22. Smith IE, Dowsett M, Ebbs SR, Dixon JM, Skene A, Blohmer JU, Ashley SE, Francis S, Boeddinghaus I, Walsh G: Neoadjuvant treatment of postmenopausal breast cancer with anastrozole, tamoxifen, or both in combination: the Immediate Preoperative Anastrozole, Tamoxifen, or Combined with Tamoxifen (IMPACT) multicenter double-blind randomized trial. J Clin Oncol 2005, 23:5108-5116.

23. Desmedt C, Piette F, Loi S, Wang Y, Lallemand F, Haibe-Kains B, Viale G, Delorenzi M, Zhang Y, d'Assignies MS, Bergh J, Lidereau R, Ellis P, Harris AL, Klijn JG, Foekens JA, Cardoso F, Piccart MJ, Buyse M, Sotiriou C, TRANSBIG Consortium: Strong time dependence of the 76-gene prognostic signature for node-negative breast cancer patients in the TRANSBIG multicenter independent validation series. Clin Cancer Res 2007, 13:3207-3214

24. Wang $Y$, Klijn JG, Zhang Y, Sieuwerts AM, Look MP, Yang F, Talantov D, Timmermans M, Meijer-van Gelder ME, Yu J, Jatkoe T, Berns EM, Atkins D, Foekens JA: Gene-expression profiles to predict distant metastasis of lymph-node-negative primary breast cancer. Lancet 2005, 365:671-679.

25. Whitfield ML, George LK, Grant GD, Perou CM: Common markers of proliferation. Nat Rev Cancer 2006, 6:99-106.

26. Dai H, van't Veer L, Lamb J, He YD, Mao M, Fine BM, Bernards R, van de Vijver M, Deutsch P, Sachs A, Stoughton R, Friend S: A cell proliferation signature is a marker of extremely poor outcome in a subpopulation of breast cancer patients. Cancer Res 2005, 65:4059-4066.

27. Whitfield ML, Sherlock G, Saldanha AJ, Murray JI, Ball CA, Alexander KE, Matese JC, Perou CM, Hurt MM, Brown PO, Botstein D: Identification of genes periodically expressed in the human cell cycle and their expression in tumors. Mol Biol Cell 2002, 13:1977-2000.

28. Metivier R, Penot G, Hubner MR, Reid G, Brand H, Kos M, Gannon F: Estrogen receptor-alpha directs ordered, cyclical, and combinatorial recruitment of cofactors on a natural target promoter. Cell 2003, 115:751-763.

29. Mackay A, Urruticoechea A, Dixon JM, Dexter T, Fenwick K, Ashworth A, Drury S, Larionov A, Young O, White S, Miller WR, Evans DB, Dowsett M: Molecular response to aromatase inhibitor treatment in primary breast cancer. Breast Cancer Res 2007, 9:R37.

30. Miller WR, Larionov AA, Renshaw L, Anderson TJ, White S, Murray J, Murray E, Hampton G, Walker JR, Ho S, Krause A, Evans DB, Dixon JM: Changes in breast cancer transcriptional profiles after treatment with the aromatase inhibitor, letrozole. Pharmacogenet Genomics 2007, 17:813-826.

31. Kantarjian $H$, Giles F, Wunderle L, Bhalla K, O'Brien S, Wassmann B, Tanaka C, Manley P, Rae P, Mietlowski W, Bochinski K, Hochhaus A, Griffin JD, Hoelzer D, Albitar M, Dugan M, Cortes J, Alland L, Ottmann OG: Nilotinib in imatinib-resistant CML and Philadelphia chromosome-positive ALL. N Engl J Med 2006, 354:2542-2551.
32. Kurokawa H, Lenferink AE, Simpson JF, Pisacane PI, Sliwkowski MX, Forbes JT, Arteaga CL: Inhibition of HER2/neu (erbB-2) and mitogenactivated protein kinases enhances tamoxifen action against HER2overexpressing, tamoxifen-resistant breast cancer cells. Cancer Res 2000, 60:5887-5894.

33. Shou J, Massarweh S, Osborne CK, Wakeling AE, Ali S, Weiss H, Schiff R: Mechanisms of tamoxifen resistance: increased estrogen receptor-HER2/ neu cross-talk in ER/HER2-positive breast cancer. J Natl Cancer Inst 2004, 96:926-935.

34. Martin LA, Farmer I, Johnston SR, Ali S, Marshall C, Dowsett M: Enhanced estrogen receptor (ER) alpha, ERBB2, and MAPK signal transduction pathways operate during the adaptation of MCF-7 cells to long term estrogen deprivation. J Biol Chem 2003, 278:30458-30468.

35. Pancholi S, Lykkesfeldt AE, Hilmi C, Banerjee S, Leary A, Drury S, Johnston S, Dowsett M, Martin LA: ERBB2 influences the subcellular localization of the estrogen receptor in tamoxifen-resistant MCF-7 cells leading to the activation of AKT and RPS6KA2. Endocr Relat Cancer 2008, 15:985-1002.

36. Miller WR, Larionov A, Renshaw L, Anderson TJ, Walker JR, Krause A, Sing T, Evans DB, Dixon JM: Gene expression profiles differentiating between breast cancers clinically responsive or resistant to letrozole. J Clin Oncol 2009, 27:1382-1387.

37. Miller WR, Larionov A: Changes in expression of oestrogen regulated and proliferation genes with neoadjuvant treatment highlight heterogeneity of clinical resistance to the aromatase inhibitor, letrozole. Breast Cancer Res 2010, 12:R52.

38. Muhlethaler-Mottet A, Di Berardino W, Otten LA, Mach B: Activation of the MHC class II transactivator CIITA by interferon-gamma requires cooperative interaction between Stat1 and USF-1. Immunity 1998, 8:157-166.

39. Teschendorff AE, Miremadi A, Pinder SE, Ellis IO, Caldas C: An immune response gene expression module identifies a good prognosis subtype in estrogen receptor negative breast cancer. Genome Biol 2007, 8:R157.

40. Desmedt C, Haibe-Kains B, Wirapati P, Buyse M, Larsimont D, Bontempi G, Delorenzi M, Piccart M, Sotiriou C: Biological processes associated with breast cancer clinical outcome depend on the molecular subtypes. Clin Cancer Res 2008, 14:5158-5165.

41. Wu G, Xing M, Mambo E, Huang X, Liu J, Guo Z, Chatterjee A, Goldenberg D, Gollin SM, Sukumar S, Trink B, Sidransky D: Somatic mutation and gain of copy number of PIK3CA in human breast cancer. Breast Cancer Res 2005, 7:R609-616.

42. Bachman KE, Argani P, Samuels Y, Silliman N, Ptak J, Szabo S, Konishi H, Karakas B, Blair BG, Lin C, Peters BA, Velculescu VE, Park BH: The PIK3CA gene is mutated with high frequency in human breast cancers. Cancer Biol Ther 2004, 3:772-775.

43. Saal LH, Holm K, Maurer M, Memeo L, Su T, Wang X, Yu JS, Malmstrom PO, Mansukhani M, Enoksson J, Hibshoosh H, Borg A, Parsons R: PIK3CA mutations correlate with hormone receptors, node metastasis, and ERBB2, and are mutually exclusive with PTEN loss in human breast carcinoma. Cancer Res 2005, 65:2554-2559.

44. Shoman N, Klassen S, McFadden A, Bickis MG, Torlakovic E, Chibbar R: Reduced PTEN expression predicts relapse in patients with breast carcinoma treated by tamoxifen. Mod Pathol 2005, 18:250-259.

45. Tokunaga E, Kimura Y, Mashino K, Oki E, Kataoka A, Ohno S, Morita M, Kakeji Y, Baba H, Maehara Y: Activation of PI3K/Akt signaling and hormone resistance in breast cancer. Breast Cancer 2006, 13:137-144.

46. Creighton CJ, Casa A, Lazard Z, Huang S, Tsimelzon A, Hilsenbeck SG, Osborne CK, Lee AV: Insulin-like growth factor-I activates gene transcription programs strongly associated with poor breast cancer prognosis. J Clin Oncol 2008, 26:4078-4085.

47. Bachelot T, Bourgier C, Cropet C, Guastalla J-P, Ferrero J-M, LegerFalandry C, Soulie P, Eymard J-C, Denled M, Spaeth D, Legouffe E, Delozier T, El Kouri C, Chidiac J: TAMRAD: a GINECO randomized phase II trial of everolimus in combination with tamoxifen versus tamoxifen alone in patients (pts) with hormone-receptor positive, HER2 negative metastatic breast cancer $(\mathrm{MBC})$ with prior exposure to aromatase inhibitors (Al) [abstract]. Cancer Research 2011, 70:S1-6.

48. Baselga J, Campone M, Piccart M, Burris HA 3rd, Rugo HS, Sahmoud T, Noguchi S, Gnant M, Pritchard KI, Lebrun F, Beck JT, Ito Y, Yardley D, Deleu I, Perez A, Bachelot T, Vittori L, Xu Z, Mukhopadhyay P, Lebwohl D, Hortobagyi GN: Everolimus in postmenopausal hormone-receptorpositive advanced breast cancer. N Engl J Med 2012, 366:520-529. 
49. Dibb NJ, Dilworth SM, Mol CD: Switching on kinases: oncogenic activation of BRAF and the PDGFR family. Nat Rev Cancer 2004, 4:718-727.

50. Yuan ZM, Huang Y, Whang Y, Sawyers C, Weichselbaum R, Kharbanda S, Kufe D: Role for c-Abl tyrosine kinase in growth arrest response to DNA damage. Nature 1996, 382:272-274.

51. Brasher BB, Van Etten RA: c-Abl has high intrinsic tyrosine kinase activity that is stimulated by mutation of the Src homology 3 domain and by autophosphorylation at two distinct regulatory tyrosines. J Biol Chem 2000, 275:35631-35637.

52. Wen ST, Jackson PK, Van Etten RA: The cytostatic function of c-Abl is controlled by multiple nuclear localization signals and requires the p53 and Rb tumor suppressor gene products. EMBO J 1996, 15:1583-1595.

53. Taagepera S, McDonald D, Loeb JE, Whitaker LL, McElroy AK, Wang JY, Hope TJ: Nuclear-cytoplasmic shuttling of C-ABL tyrosine kinase. Proc Natl Acad Sci USA 1998, 95:7457-7462

54. Druker BJ, Talpaz M, Resta DJ, Peng B, Buchdunger E, Ford JM, Lydon NB, Kantarjian H, Capdeville R, Ohno-Jones S, Sawyers CL: Efficacy and safety of a specific inhibitor of the BCR-ABL tyrosine kinase in chronic myeloid leukemia. N Engl J Med 2001, 344:1031-1037.

55. Paulsson J, Sjoblom T, Micke P, Ponten F, Landberg G, Heldin CH, Bergh J, Brennan DJ, Jirstrom K, Ostman A: Prognostic significance of stromal platelet-derived growth factor beta-receptor expression in human breast cancer. Am J Pathol 2009, 175:334-341.

56. Leary AF, Drury S, Detre S, Pancholi S, Lykkesfeldt AE, Martin LA, Dowsett M, Johnston SR: Lapatinib restores hormone sensitivity with differential effects on estrogen receptor signaling in cell models of human epidermal growth factor receptor 2-negative breast cancer with acquired endocrine resistance. Clin Cancer Res 2010, 16:1486-1497.

57. Chen Y, Alvarez EA, Azzam D, Wander SA, Guggisberg N, Jorda M, Ju Z, Hennessy BT, Slingerland JM: Combined Src and ER blockade impairs human breast cancer proliferation in vitro and in vivo. Breast Cancer Res Treat 2011, 128:69-78.

58. He X, Zheng Z, Song T, Wei C, Ma H, Ma Q, Zhang Y, Xu Y, Shi W, Ye Q, Zhong $\mathrm{H}$ : c-Abl regulates estrogen receptor alpha transcription activity through its stabilization by phosphorylation. Oncogene 2010, 29:2238-2251.

59. Oh AS, Lahusen JT, Chien CD, Fereshteh MP, Zhang X, Dakshanamurthy $S$, XU J, Kagan BL, Wellstein A, Riegel AT: Tyrosine phosphorylation of the nuclear receptor coactivator AIB1/SRC-3 is enhanced by Abl kinase and is required for its activity in cancer cells. Mol Cell Biol 2008, 28:6580-6593.

60. Arun B, Walters R, Brewster A, Rivera E, Valero V, Bast R, Theriault RL, Green M, Green M, Hortobagyi GN: The combination of letrozole and imatinib mesylate for metastatic breast cancer [abstract]. ASCO Breast Cancer Symposium 2009.

61. Chow LW, Yip AY, Loo WT, Toi M: Evaluation of neoadjuvant inhibition of aromatase activity and signal transduction in breast cancer. Cancer Lett 2008, 262:232-238

doi:10.1186/bcr3191

Cite this article as: Weigel et al:: Preclinical and clinical studies of estrogen deprivation support the PDGF/Abl pathway as a novel therapeutic target for overcoming endocrine resistance in breast cancer. Breast Cancer Research 2012 14:R78.

\section{Submit your next manuscript to BioMed Central and take full advantage of:}

- Convenient online submission

- Thorough peer review

- No space constraints or color figure charges

- Immediate publication on acceptance

- Inclusion in PubMed, CAS, Scopus and Google Scholar

- Research which is freely available for redistribution

Submit your manuscript at www.biomedcentral.com/submit
Biomed Central 